\title{
Programa de Melhoria do Acesso e da Qualidade da Atenção Básica: uma análise das principais mudanças normativas
}

\author{
| ${ }^{1}$ Pauline Cavalcanti, ${ }^{2}$ Michelle Fernandez |
}

Resumo: Este artigo realizou uma análise das principais mudanças no arcabouço normativo do Programa de Melhoria do Acesso e da Qualidade da Atenção Básica, a partir de documentos oficiais do Ministério da Saúde divulgados de julho 2011 a julho de 2019. Os achados revelam que a maioria das mudanças não ficaram claras, dificultando a compreensão do desenho do programa e o acompanhamento dos resultados das equipes de atenção básica. Ocorreram mudanças no desenho geral do programa e mais intrinsecamente às fases ou componentes. Foram modicadas a arquitetura das fases; as regras na adesão ao programa; a forma de verificação da autoavaliação; o monitoramento dos indicadores em função da implantação de um novo sistema de informação ou por deficiências técnicas para utilização de determinado indicador; a avaliação externa com relação às regras para solicitação e prazos para receber a avaliação, ao descredenciamento das equipes, e aos parâmetros e método adotados; e a certificação mais radicalmente na valoração dos componentes e na metodologia de cálculo e categorias de classificação das equipes. O programa apostou em diversas estratégias para qualificação da atenção básica. Embora com limitações e incompletudes, percebê-las é uma oportunidade de buscar soluçôes viáveis para o refinamento da política de saúde.

> Palavras-chave: políticas públicas de saúde; Atenção Básica; monitoramento; qualidade em saúde, acesso e avaliação; melhoria da qualidade.

\footnotetext{
${ }^{1}$ Instituto Aggeu Magalhães, Fundação Oswaldo Cruz. RecifePE, Brasil (pauline.cavalcanti@ gmail.com).

ORCID: 0000-0002-1743-2075

${ }^{2}$ Instituto Aggeu Magalhães, Fundação Oswaldo Cruz. RecifePE, Brasil (michelle.vfernandez@ gmail.com).

ORCID: 0000-0003-0224-0991
}

Recebido em: 12/04/2020 Aprovado em: 28/07/2020 Revisado em: 15/09/2020 


\section{Introdução}

No início de 2011, após várias reunióes entre a Presidência da República e a equipe do Ministério da Saúde (MS), a Atenção Básica (AB) foi definida como prioridade para o SUS. A partir disso, delinearam-se os desafios condicionantes do desenvolvimento da área, posteriormente também debatidos entre os atores tripartites e no Conselho Nacional de Saúde, visando à produção de consenso acerca dos problemas que deveriam ser foco de atuação por meio de açóes e programas da Política Nacional de Atenção Básica - PNAB (PINTO; SOUSA; FERLA, 2014).

No mesmo ano a PNAB foi revisada, e foi lançada a estratégia "Saúde Mais Perto de Você" para enfrentar os gargalos à expansão e desenvolvimento da $\mathrm{AB}$ (BRASIL, 2012b). Nesse contexto, o tema do acesso e da qualidade da AB ganhou destaque dentro do MS, com o surgimento do Programa de Melhoria do Acesso e da Qualidade da Atenção Básica (PMAQ-AB), visando induzir melhoria do atendimento e do cuidado prestado à população (BRASIL, 2012a).

$O$ PMAQ-AB é visto como uma iniciativa conectada às mudanças ocorridas no MS, que apontam para a centralidade da $\mathrm{AB}$ e o redesenho da regionalização e do financiamento do Sistema Único de Saúde (SUS) e estratégias avaliativas (GOMES; MERHY, 2016). Considerado um revelador da política, o programa é visto como o que melhor sintetiza a PNAB, pois se articula com diversas iniciativas, estabelecendo uma relação de síntese e sinergia com quase todas (PINTO; SOUSA; FERLA, 2014).

O programa objetiva obter um padrão de qualidade dos serviços que seja comparável nacional, regional e localmente, visando permitir maior efetividade das ações governamentais voltadas à $\mathrm{AB}$, bem como acompanhar os resultados alcançados para mensurar os efeitos das políticas de saúde, garantir a transparência dos processos de gestão do SUS, publicizar os resultados alcançados e fortalecer o controle social (BRASIL, 2012a). Para tanto, propôs o desenvolvimento de açóes conjuntas dos entes federados, buscando garantir o acesso e a qualidade dos serviços da $\mathrm{AB}$, a partir de um processo de indução ao monitoramento e avaliação, no intuito de enfrentar o persistente desafio da institucionalização das açôes nesse sentido, que afeta, sobretudo, o cotidiano da gestão e das equipes de saúde (REDE APS, 2018).

Vale lembrar que em 2017, durante a implementação do PMAQ-AB, a PNAB passou por mais uma revisão. Desta vez, em meio a uma conjuntura de crise política e econômica do país, com o MS assumindo uma agenda consoante com o 
contexto macropolítico deletério às políticas sociais, diferentemente do ocorrido em 2011 (MELO et al., 2018), que tinha um panorama de inclusão de diversos atores políticos na definição de prioridades e de novos investimentos financeiros para a $\mathrm{AB}$ (PINTO; SOUSA; FERLA, 2014).

O momento inoportuno e a forma sectária e unilateral cuja política foi produzida resultou em um conteúdo que oferece condiçôes para o desmonte da Estratégia Saúde da Família, considerando o cenário de agravamento do subfinanciamento e as flexibilizaçôes declaradas na política. Embora a PNAB presuma a realização de ações de monitoramento e avaliação, essa questão foi abordada de forma restrita, apontando para estratégias no âmbito conceitual e discursivo, sem dispositivos concretos para a sua efetivação (MELO et al., 2018). Logo, se no plano formal, a PNAB dita os rumos da $A B$, suas fragilidades e deficiências podem ser percebidas concretamente no exemplo do PMAQ-AB, que outrora reacendeu o debate acerca do monitoramento e avaliação da $\mathrm{AB}$ e trouxe novos recursos financeiros, mas atualmente essas questôes se resumem a um fragmento textual sobre a aplicação dos recursos financeiros federais conforme o desempenho dos serviços de $\mathrm{AB}$.

O PMAQ-AB, criado em 2011, foi implantado em um curto espaço de tempo (CAVALCANTI, 2014) e encerrado em 2019. Catalisou várias discussóes e trouxe à tona problemas já conhecidos que transversalizam os espaços de debate no SUS para os quais não há soluções fáceis e prontas. Portanto, não serão solucionados sem múltiplas iniciativas convergentes e cooperação de diversos atores envolvidos na construção das políticas de saúde. O programa tornou-se então um assunto polêmico, acumulando diversas visóes e críticas sobre seus objetivos, métodos e resultados, ainda mais que durante sua vigência acumulou um vasto conteúdo normativo e alteraçôes processuais, seja, em termos gerais ou específicos, complexificando-o cada vez mais.

Este artigo analisa as principais mudanças no arcabouço normativo do PMAQ$\mathrm{AB}$, a partir de documentos oficiais do programa, com vistas a identificar as alteraçôes ocorridas e produzir uma síntese que favoreça a reflexão sobre o seu desenho.

\section{Metodologia}

As políticas públicas são em iniciativas dos governos para responder às demandas, problemas e conflitos previamente identificados e elencados, sendo traduzidas em programas. $\mathrm{Na}$ construção da política estáo presentes diversos elementos que se 
misturam e tomam contornos, representando uma gama de ideias e interesses de vários atores dotados de distinto poder decisório (MATTOS; BAPTISTA, 2015).

A análise de políticas possibilita um rico olhar explicativo sobre as políticas públicas, auxiliando na compreensão de seus elementos constitutivos e sobre os processos que envolvem sua construção. Quando se decide analisar uma política (no todo ou parcialmente), deve-se considerar as singularidades relativas à evolução, modificação e inovação, de modo a destacar as estratégias de ação estatal e a abrangência das mudanças introduzidas ao longo de certo período, associando a análise o emaranhado de relaçôes que se configuram, a diversidade de sujeitos e suas disputas nesse processo. À luz da análise de políticas, este estudo considerou as diversas alteraçóes no arcabouço normativo do PMAQ-AB como resultado do processo social e político (MATTOS; BAPTISTA, 2015) no que tange a sua formulação e afeta seu projeto político.

Trata-se de pesquisa qualitativa, que compreende um estudo de caso sobre o PMAQ-AB desenvolvido por meio de uma análise documental. As fontes documentais foram adquiridas na página da Internet do PMAQ-AB no site da Secretaria de Atenção Primária à Saúde (SAPS) do MS, onde se realizou um levantamento dos documentos oficiais que fundamentaram o programa, publicados no período de julho 2011 a julho de 2019.

Ao final, foram selecionados 14 documentos considerados relevantes por conter informaçóes essenciais sobre o programa, a saber:

- Portaria no 1.654, de 19 de julho de 2011, que institui o PMAQ-AB (BRASIL, 2011);

- Portaria no 1.645, de 2 de outubro de 2015, que revisou o PMAQ-AB (BRASIL, 2015a);

- PMAQ-AB: Manual Instrutivo (BRASIL, 2012a);

- PMAQ-AB: Manual Instrutivo para as Equipes de Atenção Básica - EAB e Núcleos de Apoio à Saúde da Família - NASF (BRASIL, 2013a);

- PMAQ-AB: Manual Instrutivo para as EAB e NASF (BRASIL, 2015b);

- Nota Metodológica da Certificação das EAB participantes do PMAQ (BRASIL, 2013c);

- Nota Metodológica da Certificação das EAB (BRASIL, 2015c);

- Nota Metodológica da Certificação dos NASF (BRASIL, 2015d); 
- Nota Metodológica da Certificação das EAB participantes do PMAQ (BRASIL, 2018a);

- Nota Metodológica da Certificação dos NASF (BRASIL, 2018b);

- Instrumento de Avaliação Externa do Saúde Mais Perto de Você (BRASIL, 2012c);

- Instrumento de Avaliação Externa para as EAB, Saúde Bucal e NASF (BRASIL, 2013b);

- Instrumento de Avaliação Externa para as EAB, Saúde Bucal e NASF (BRASIL, 2017b);

- Autoavaliação para Melhoria do Acesso e da Qualidade da AB - AMAQ (2017a).

Cabe esclarecer que não foi objetivo deste estudo pormenorizar as inúmeras alteraçôes adotadas nos instrumentos avaliativos. Tal análise demanda investigação específica e detalhada capaz de pontuar as mudanças realizadas, seja na sua arquitetura geral ou nos parâmetros definidos, para compreender os requisitos que visam atender. Também não é foco aqui analisar detalhadamente as modificaçôes e repercussóes relativas aos recursos financeiros, dada a relevância do tema, com destaque para a alteração nas normas sobre o financiamento e a transferência dos recursos federais do SUS por meio da Portaria no 3.992, de 28 de dezembro de 2017, e a reorientação dos recursos financeiros do PMAQ-AB dentro de uma nova política governamental, o Programa Previne Brasil, em 2019. Além disso, uma análise inicial mostrou a necessidade de maior aprofundamento com detalhamento dos valores associados aos diversos tipos/modalidades de equipes no programa e sua relação com as normas referentes ao financiamento da $\mathrm{AB}$ no SUS e regras gerais do programa.

Os documentos foram reunidos e catalogados para leitura e seleção das partes consideradas essenciais para a análise. A riqueza dos dados fez surgir uma matriz de análise, representando cada fase do programa e evidenciando elementos conceituais, discursivos e operacionais presentes nos três ciclos. Ela serviu para entender o programa no decorrer das fases, em cada ciclo, possibilitando depois a comparação os elementos que expressam as mudanças do PMAQ-AB, sendo traduzida nos quadros presentes nos resultados do estudo.

As interpretaçóes e explicações apresentadas resultam da combinação de análise de políticas e uma análise de conteúdo. As categorias temáticas guardam 
correspondência com as fases constitutivas do programa como forma de tornar a leitura mais compreensível, mantendo uma sequência lógica de exposição dos dados. ${ }^{1}$

\section{Resultados e Discussão}

O desenho do PMAQ-AB propóe um conjunto de estratégias de qualificação, acompanhamento e avaliação do trabalho das equipes de saúde. No $1^{\circ}$ e $2^{\circ}$ ciclos, o programa organizava-se em quatro fases: Adesão e Contratualização; Desenvolvimento; Avaliação Externa; e Recontratualização. No $3^{\circ}$ ciclo, a fases passaram a ser três: Adesão e Contratualização; Certificação; Recontratualização, atravessadas pelo Eixo Estratégico Transversal de Desenvolvimento.

Essa mudança mais geral no desenho do programa não representou a exclusão de fases ou componentes. Ocorreu uma restruturação, agregando elementos que poderiam pertencer a uma mesma etapa e enfatizando alguns componentes, bem como seu entendimento conceitual. Assim, a fase de Desenvolvimento adquiriu nomenclatura nova denominada de Eixo Estratégico Transversal de Desenvolvimento, "entendido como transversal a todas as fases, de maneira a assegurar que as açôes de promoçáo da melhoria da qualidade possam ser desenvolvidas em todas as etapas do ciclo do programa" (BRASIL, 2015a; 2015b), reforçando uma ideia de continuidade no desenvolvimento das açôes empreendidas, pelas equipes de $\mathrm{AB}$ e gestores das três esferas, na intenção de alcançar melhores resultados. A Avaliação Externa, por sua vez, foi encaixada na Certificação, o que faz sentido diante da compreensão que a última inclui a primeira. Essa nova terminologia evidência o resultado final do processo avaliativo, deixando de realçar apenas parte dele. Outros componentes da Certificação possuem características mais processuais e são apontados como potentes promotores de mudanças e, permaneceram integrando o Eixo.

Cada ciclo do programa passa por todas as fases. As normativas previam um ciclo a cada 24 meses, porém, isso nunca aconteceu. O $1^{\circ}$ ciclo foi o mais curto $(12$ meses: outubro de 2011-janeiro de 2013), o $2^{\circ}$ ciclo (31 meses: fevereiro de 2013-setembro de 2015) e o $3^{\circ}$ ciclo (43 meses: outubro de 2015-maio de 2019) foram mais longos.

O $1^{\circ}$ ciclo foi acelerado visando à implantação do programa (FAUSTO; FONSECA, 2013). Já o $3^{\circ}$ ciclo tornou-se o mais longo. Durante meses, o MS manteve apenas o rito administrativo, repassando recursos vinculados ao programa conforme os resultados do ciclo anterior. Mas, em 2019, simultaneamente à 
divulgação dos resultados do $3^{\circ}$ ciclo, foi anunciado o fim do programa e o redirecionamento dos recursos dentro da nova política governamental (ABRASCO, 2019). Segundo Melo et al. (2018), a partir de 2014 transiçôes observadas nos cargos do alto escaláo do MS revelaram novas prioridades e direcionamentos para o SUS. Frente a isso, diversas pautas ministeriais foram, em algum grau, afetadas por inoperância e reestruturaçôes em consonância com o cenário político global do governo federal que, evidentemente, redireciona as políticas governamentais formuladas nos ministérios.

\section{Adesão e contratualizaçáo}

Realizada por meio de sistema do MS, a Adesão e Contratualização foi definida inicialmente como um processo permanente, mas isso mudou, passando a ter períodos e prazos determinados. Estava previsto um processo contínuo para a homologação dos municípios e equipes no programa, que findou acontecendo só uma vez por ciclo. As condiçóes para permanência das equipes no programa foram sendo flexibilizadas a cada ciclo (ver quadro 1).

Quadro 1. Adesẫo e Contratualização ou Recontratualização por ciclo.

\begin{tabular}{|c|c|}
\hline $1^{\circ}$ ciclo & $3^{\circ}$ ciclo \\
\hline $\begin{array}{l}\text { Adesão e Contratualização } \\
\text { (novas equipes) }\end{array}$ & $\begin{array}{l}\text { Adesão e Contratualização (novas equipes) } \\
\text { Recontratualização (equipes de ciclos anteriores) }\end{array}$ \\
\hline 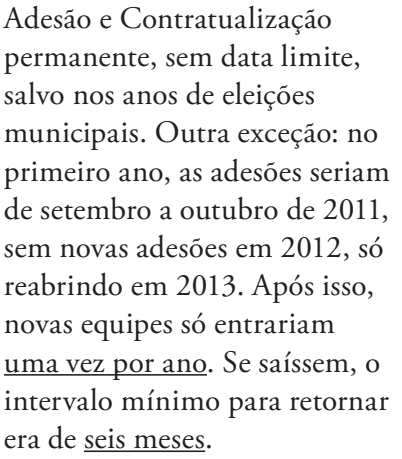 & $\begin{array}{l}\text { Adesão e Contratualização e Recontratualização em períodos e } \\
\text { prazos determinados, realizada uma vez por ciclo. Se saíssem, só } \\
\text { poderiam retornar no próximo ciclo. }\end{array}$ \\
\hline
\end{tabular}

continua... 


\begin{tabular}{|c|c|c|}
\hline $1^{\circ}$ ciclo & $2^{\circ}$ ciclo & $3^{\circ}$ ciclo \\
\hline $\begin{array}{l}\text { Os municípios podiam incluir } \\
\text { todas ou parte das equipes no } \\
\text { programa, exceto no primeiro } \\
\text { ano de implantação, que } \\
\text { se aplicou o limite de } 50 \% \\
\text { de equipes para Adesão e } \\
\text { Contratualizaçáo. Isso implicou } \\
\text { no } \underline{\text { Ranking para a priorizaçáo }} \\
\text { das adesôes. }\end{array}$ & $\begin{array}{l}\text { Não houve limite e Ranking à } \\
\text { participaçáo. }\end{array}$ & $\begin{array}{l}\text { Para novas equipes, o gestor } \\
\text { municipal fez um } \underline{\text { Ranking, }} \\
\text { considerando a prioridade } \\
\text { para participar do programa, } \\
\text { mas, sem garantia da adesão, } \\
\text { dependendo de disponibilidade } \\
\text { orçamentária. }\end{array}$ \\
\hline \multirow{2}{*}{ 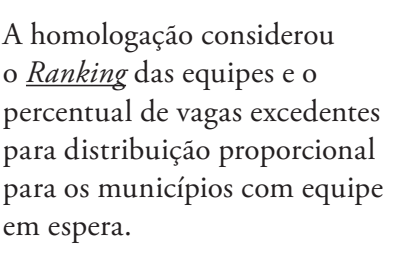 } & $\begin{array}{l}\text { A homologação considerou a } \\
\text { adesão formal do gestor. }\end{array}$ & $\begin{array}{l}\text { Para novas equipes, a } \\
\text { homologação considerou o } \\
\text { Ranking e priorizou equipes do } \\
\underline{\text { Programa Mais Médicos. }}\end{array}$ \\
\hline & \multicolumn{2}{|c|}{$\begin{array}{l}\text { Para o NASF considerou-se como critério a participação do número } \\
\text { mínimo de EAB, por modalidade. }\end{array}$} \\
\hline $\begin{array}{l}\text { Gestores e equipes acessavam } \\
\text { o sistema para a Adesão } \\
\text { e Contratualizaçáo. O } \\
\text { "responsável pela gestão" } \\
\text { acessava o sistema, realizava } \\
\text { o seu cadastro e, depois, o } \\
\text { "responsável da equipe" acessava } \\
\text { o sistema, realizava cadastro e } \\
\text { indicava a adesão da equipe. Ao } \\
\text { final, o gestor fez um Ranking } \\
\text { das equipes, em razão do limite } \\
\text { de participaçáo preestabelecido. }\end{array}$ & $\begin{array}{l}\text { Gestores e equipes acessavam } \\
\text { o sistema para a Adesão } \\
\text { e Contratualização/ } \\
\text { Recontratualização, em dois } \\
\text { momentos. No primeiro, o } \\
\text { responsável pela gestão declarou } \\
\text { a quantidade de equipes para } \\
\text { adesão (até 100\%). O segundo } \\
\text { destinou-se à adesão formal } \\
\text { de, no máximo, a quantidade } \\
\text { de equipes declaradas } \\
\text { anteriormente. Depois, os } \\
\text { procedimentos foram similares } \\
\text { ao } 1^{\circ} \text { ciclo. No final, isso } \\
\text { mudou, só os gestores a } \\
\text { realizavam a adesão. }\end{array}$ & $\begin{array}{l}\text { Apenas gestores acessavam } \\
\text { o sistema para a Adesão } \\
\text { e Contratualização/ } \\
\text { Recontratualização, realizada } \\
\text { em duas etapas: Etapa } 1 \text { - EAB } \\
\text { e equipe de saúde bucal (ESB) e } \\
\text { a Etapa } 2 \text { - NASF. Em ambos os } \\
\text { casos, o responsável pela gestão } \\
\text { acessava o sistema, realizava } \\
\text { cadastro/atualizava e indicava as } \\
\text { equipes que iriam participar. }\end{array}$ \\
\hline $\begin{array}{l}\text { A Contratualizaçáo previa } \\
\text { o envio pelo sistema do } \\
\text { Termo de Compromisso } \\
\text { (TC) da equipe e o da gestão } \\
\text { municipal, assinados; e do TC } \\
\text { elou resolução da Comissão } \\
\text { Intergestores Bipartite assinado } \\
\text { com compromissos do Estado e } \\
\text { Município. }\end{array}$ & \multicolumn{2}{|c|}{$\begin{array}{l}\text { A Contratualização previa a assinatura de TC da equipe com a } \\
\text { gestão municipal, verificado na Avaliação Externa. }\end{array}$} \\
\hline
\end{tabular}

continua... 


\begin{tabular}{|c|c|c|}
\hline $1^{\circ}$ ciclo & $2^{\circ}$ ciclo & $3^{\circ}$ ciclo \\
\hline $\begin{array}{l}\text { Condiçôes para permanência } \\
\text { no programa: adequação às } \\
\text { exigências que disciplinam o } \\
\text { pagamento do Piso da Atenção } \\
\text { Básica Variável (PAB variável); } \\
\text { alimentaçáo mensal do Sistema } \\
\text { de Informaçáo da AB; não piora } \\
\text { em mais de um desvio-padrão } \\
\text { por três meses ou mais no } \\
\text { escore dos indicadores de saúde; } \\
\text { não verificação pelos órgãos } \\
\text { de controle e sistema nacional } \\
\text { de auditoria de ausência das } \\
\text { condiçóes certificadas; e } \\
\text { garantia da identificação visual } \\
\text { do serviço. }\end{array}$ & $\begin{array}{l}\text { Condições para permanência } \\
\text { no programa: adequação às } \\
\text { exigências que disciplinam o } \\
\text { pagamento do PAB Variável } \\
\text { e na portaria no } 548 \text { de } 04 \text { de } \\
\text { abril de } 2013 \text {; alimentação do } \\
\text { Sistema de Informação nos } \\
\text { meses indicados; e aplicação das } \\
\text { Regras de Sinalização Externa e } \\
\text { Interna da unidade. }\end{array}$ & $\begin{array}{l}\text { Condiçóes para permanência } \\
\text { no programa: adequação às } \\
\text { exigências que disciplinam o } \\
\text { pagamento do PAB Variável e na } \\
\text { portaria no } 548 \text { de } 04 \text { de abril de } \\
\text { 2013; e alimentação do Sistema } \\
\text { de Informação. }\end{array}$ \\
\hline $\begin{array}{l}\text { Podiam participar do programa } \\
\text { equipes de } \mathrm{AB} \text { (eSF ou } \\
\text { parametrizada) com ou sem ESB. }\end{array}$ & \multicolumn{2}{|c|}{ Além das já citadas equipes, incluíram-se os NASFs. } \\
\hline \multirow[t]{2}{*}{$\begin{array}{l}\text { Adesão e Contratualização } \\
\text { conjunta das EAB e ESB, não } \\
\text { sendo possível participar uma } \\
\text { sem a outra. }\end{array}$} & $\begin{array}{l}\text { Adesão e Contratualização/ } \\
\text { Recontratualização das EAB e } \\
\text { ESB separada. A EAB poderia } \\
\text { participar isoladamente, mas, a } \\
\text { ESB só aderia se EAB vinculada } \\
\text { participasse. }\end{array}$ & $\begin{array}{l}\text { A Adesão e Contratualizaçáo/ } \\
\text { Recontratualizaçáo conjunta das } \\
\text { EAB e ESB, não sendo possível } \\
\text { participar uma sem a outra. }\end{array}$ \\
\hline & \multicolumn{2}{|c|}{ O NASF dependia da adesão da EAB. } \\
\hline
\end{tabular}

Fonte: as autoras.

Poderiam participar do programa EAB e ESB e os NASF, a partir do $2^{\circ}$ ciclo. No $1^{\circ}$ ciclo, a adesão das EAB e ESB foi conjunta; no $2^{\circ}$ ciclo o processo foi separado; e no $3^{\circ}$ ciclo voltou a ser conjunta. A participação do NASF sempre esteve condicionada à da EAB (quadro 1). Acredita-se que a adesão isolada, como permitido no $2^{\circ}$ ciclo, pode levar à fragmentação do trabalho das equipes, pois significa que parte da equipe participa do PMAQ-AB e outra parte não está incluída. Isso parece contraditório quando se trata de um processo avaliativo que visa induzir a melhoria do serviço que, portanto, deveria propiciar mais integração na perspectiva de convergência dos esforços para ofertar açóes mais abrangentes e resolutivas e garantir o funcionamento adequado da unidade. Essa reflexáo compreende a equipe como um sistema que possui inter-relaçôes e interdependências com outras equipes e com a comunidade. 
Situaçôes observadas na Avaliação Externa, como a existência de ESB de referência para mais de uma $\mathrm{EAB}$ ou atuando em local diferente desta; da ausência de profissionais, sobretudo de nível superior na ESB; e equipes atuando na mesma unidade com processos de trabalho apartados (FAUSTO; FONSECA, 2013) trazem questionamentos sobre o formato da adesão e participação das equipes. As oscilaçóes nas regras da adesão podem estar relacionadas com disputas de concepções e impasses que permeiam o processo decisório (MATTOS; BAPTISTA, 2015).

No $1^{\circ}$ ciclo do PMAQ-AB, houve limitação à participação, gerando um ranking de equipes por município, mas no ciclo seguinte a restrição foi suprimida. No 3 o ciclo, o ranking reapareceu para a priorização de novas equipes no programa. $\mathrm{O}$ principal motivo pode estar relacionado à disponibilidade orçamentária do MS, que remete ao início de grave crise política e econômica no país em 2014 e 2015, com impacto sobre o SUS (MELO et al., 2018). Em última análise, como a participação no programa era voluntária, a decisão sobre a Adesão e Contratualização das equipes estava na esfera local de negociação. Todavia, houve casos nos quais os gestores aderiram ou retiraram equipes sem diálogo e desconsiderando o potencial de se estabelecer negociaçóes que promovam adesão consciente e responsabilização dos diversos atores, gerando questionamentos das equipes, ao MS e às instituiçôes de ensino e pesquisa executoras da Avaliação Externa, sobre a necessidade de concordância e ausência de informação (FAUSTO; FONSECA, 2013; GOMES; BARBOSA; FERLA, 2016).

\section{Desenvolvimento para Eixo Estratégico Transversal de Desenvolvimento}

O desenvolvimento propóe estratégias para o aprimoramento das práticas de gestão e de cuidado, parte delas náo eram obrigatórias (ver quadro 2), exceto o monitoramento (exigência para a Certificação). 
Quadro 2. Fase de Desenvolvimento/Eixo Estratégico Transversal de Desenvolvimento por ciclo

\begin{tabular}{|c|c|c|}
\hline $1^{0}$ ciclo & $2^{\circ}$ ciclo & $3^{\circ}$ ciclo \\
\hline \multicolumn{2}{|c|}{$\begin{array}{l}\text { Desenvolvimento composto pelas estratégias de Autoavaliação, } \\
\text { Monitoramento dos indicadores, Educação Permanente e Apoio } \\
\text { Institucional. }\end{array}$} & $\begin{array}{l}\text { Eixo Estratégico Transversal de } \\
\text { Desenvolvimento composto pelas } \\
\text { estratégias dos ciclos anteriores, e } \\
\text { pela Cooperaçáo Horizontal. }\end{array}$ \\
\hline
\end{tabular}

Autoavaliação realizada por meio do instrumento do MS, o AMAQ, ou de outros instrumentos definidos pela gestấo municipal e/ou equipes.

Único AMAQ que servia
para gestores e para avaliaçáo
conjunta das EAB e ESB.

Foram selecionados 47 indicadores do $\underline{\text { Sistema de }}$ Informação da $\mathrm{AB}$ (SIAB), subdivididos em seis áreas estratégicas: saúde da mulher, saúde da criança, doenças crônicas, produção geral, doenças transmissíveis, saúde mental, e de saúde bucal para ESB. Eram 23 de monitoramento (20 EAB e 3 ESB), que não contam para a Certificação; e 24 de desempenho (20 de EAB e 4 de ESB), que contam para a Certificação.

Os indicadores foram calculados a partir dos dados enviados para a base de dados nacional do SIAB.
AMAQ para cada modalidade de equipe. Servia para a Autoavaliaçáo de gestores, EAB, ESB e NASF, separadamente. Foi disponibilizado um sistema próprio do AMAQ para registro da Autoavaliação.

O Monitoramento dos Indicadores

Monitoramento dos indicadores por seis meses. Mas, ao final, o período foi de três competências. considerou o $\underline{\text { SIAB, o eSUS-AB }}$ e outros sistemas, devendo, $o$ município informar o sistema utilizado no Módulo Eletrônico do MS.

Para as equipes com o SIAB, o processo foi semelhante ao do ciclo anterior.

Para equipes com $\underline{\text { SUS-AB }}$ verificou-se o desempenho alcançado no conjunto $\underline{\text { dos } 8}$ indicadores para $\mathrm{EAB}, 4$ para ESB e 5 para os NASFs, além da verificação de padrôes de implantação do sistema na Avaliação Externa. Os indicadores representavam áreas de saúde da mulher, saúde da criança, doenças crônicas e saúde bucal para as ESB. Os indicadores do NASF serviram para monitoramento, não influenciaram na Certificação. Os dados dos indicadores deveriam ser registrados no Módulo Eletrônico para posterior cálculo.

O Monitoramento dos indicadores considerou o $\underline{\text { SIAB }}$ e o eSUS-AB. Foram definidos 11 indicadores de desempenho (8 para as EAB, 3 para ESB e 5 para os NASFs), subdivididos em quatros grupos: Acesso e Continuidade do cuidado; Coordenação do cuidado; Resolutividade da equipe de atenção básica; e, Abrangência da oferta de serviços.

Os indicadores foram calculados a partir da base de dados do sistema de informação.

Para as equipes do Programa Mais Médicos, foram utilizados os dados coletados do Sistema de Gerenciamento de Programas (SGP) e do Sistema de Cadastro Nacional de Estabelecimentos de Saúde (SCNES).

Monitoramento dos indicadores no período de três competências.

Fonte: as autoras. 
A principal questão relacionada à Autoavaliação refere-se à forma de verificação de sua realização (quadro 2). A Autoavaliação seria registrada e averiguada a partir do registro dessa atividade em um sistema específico, mas na prática sua realização em todos os ciclos também foi verificada utilizando o Instrumento de Avaliação Externa, elaborado para conseguir captar informação dos vários instrumentos autoavaliativos utilizados pelas equipes.

A primeira versão do AMAQ direcionava-se para gestores e equipes; depois, criaram-se instrumentos para cada modalidade separadamente. Dentro da ideia de "produção de movimentos" (BRASIL, 2017a), a Autoavaliação se insere como elemento indutor da mudança de práticas, sendo reconhecida como uma ferramenta norteadora da organização do processo de trabalho das equipes (CRUZ, 2014). O discurso formal do PMAQ-AB esteve centrado em enfatizar a necessidade de interação entre os profissionais para uma avaliação ampla e profunda sobre o processo de trabalho e açóes realizadas, que resulte no planejamento das açóes, mas a disponibilização de instrumento focados em cada equipe passa uma ideia oposta, em que cada equipe faz sua Autoavaliação.

Vale destacar que o AMAQ contou com um sistema próprio (BRASIL, 2012a; 2019a), com documentos e orientaçôes sobre o processo, possibilitando ao usuário responder ao questionário, utilizar seus recursos para a construção da matriz de intervenção e gerar relatórios. Nos locais onde se tem acesso a recursos tecnológicos, essa ferramenta facilita a utilização do instrumento, o acompanhamento, compartilhamento e transparência das açóes planejadas, metas e reponsabilidades estabelecidas, sobretudo em nível local.

O Monitoramento dos Indicadores sofreu várias mudanças. Primeiramente, devido às limitaçôes técnicas e operacionais do Sistema de Informação (SI) e dos indicadores selecionados; posteriormente, em virtude da implantação do novo SI, visando à melhoria da qualidade dos dados e manejo das informaçôes de saúde relativas à $\mathrm{AB}$, levando a um período de transição de sistemas.

Nos primeiros ciclos, os indicadores do PMAQ-AB representavam áreas específicas e dividiam-se em monitoramento e desempenho, mas nem todos serviam para a Certificação. Com o eSUS-AB, buscou-se representar os princípios da $\mathrm{AB}$ e todos serviam para a Certificação. No $1^{\circ}$ ciclo só foram calculados 20 indicadores de desempenho, sendo excluídos os da saúde bucal, que foram calculados no $2^{\circ}$ ciclo para as equipes com o SIAB. Ainda neste ciclo, para as equipes com eSUS-AB, 
realizou-se o cálculo dos indicadores de desempenho das EAB e das ESB. Para os NASF verificou-se o SI utilizado no momento da Avaliação Externa. No $3^{\circ}$ ciclo, mais uma vez, não foram calculados todos os indicadores. Mas, pela primeira vez, calcularam-se indicadores do NASF (quadro 2).

O período de Monitoramento dos Indicadores previsto no $1^{\circ}$ ciclo foi encurtado e manteve-se assim nos outros ciclos (quadro 2), em decorrência de dificuldades impostas por mudanças e limitações dos SI, que afetaram sua operacionalização. No geral, a divulgação dos resultados nos indicadores sempre foi tardia e alguns nunca foram divulgados. Assim, o Monitoramento dos Indicadores do PMAQ-AB esteve focado na Certificação (CAVALCANTI, 2014). Falhas no monitoramento e na divulgação dos resultados não foram resolvidas ao longo do tempo, dificultando o uso das informações de saúde.

Os indicadores do PMAQ-AB versavam sobre a produção das equipes e processos instituídos. Eles possibilitam obter um panorama do que as equipes realizam; contudo, são insuficientes para verificar resultados relacionados à qualidade e na perspectiva da melhoria, sendo pouco utilizados para o monitoramento sistemático e contínuo, que parece assumir mais um caráter de avaliação pontual do que de monitoramento contínuo e regular (ALBUQUERQUE; MARTINS, 2017). Acredita-se também que com aperfeiçoamentos no SI e nos indicadores, e a adoção de métodos de análise mais assertivos, seria possível dar mais destaque ao monitoramento, podendo substituir até mesmo alguns elementos da avaliação in loco.

Para os NASF, em especial, o PMAQ-AB inovou ao definir indicadores específicos. A ausência de indicadores desde sua criaçáo em 2008 pelo MS tem sido motivo de críticas, conferindo dificuldades à institucionalização de açôes avaliativas. A definição de indicadores para o NASF deve ser compreendida como uma possibilidade de melhor compreensão do processo de trabalho e, consequentemente, para a adoção de estratégias que possibilitem o alcance dos resultados desejados (RODRIGUEZ; LEÃO; SOUZA, 2014).

\section{De Avaliação Externa para Certificação}

A Certificação considera o desenvolvimento de uma série de açôes, segundo parâmetros definidos no PMAQ-AB. É o momento de revelar os resultados alcançados pelas equipes e gestores participantes do programa. 
Quadrro 3. Avaliação Externa do PMAQ-AB por ciclo

\begin{tabular}{|c|c|c|}
\hline $1^{\circ}$ ciclo & $2^{\circ}$ ciclo & $3^{\circ}$ ciclo \\
\hline $\begin{array}{l}\text { Avaliação Externa realizada por } \\
\text { Instituiçóes de Ensino e Pesquisa } \\
\text { (IEP) organizadas em consórcios: } \\
\text { seis principais (que recebiam recursos } \\
\text { do MS) e } 41 \text { vinculadas a elas. }\end{array}$ & $\begin{array}{l}\text { Avaliação externa realizada } \\
\text { por IEP organizadas em } \\
\text { consórcios: oito principais e } \\
38 \text { vinculadas a elas. }\end{array}$ & $\begin{array}{l}\text { Avaliação externa realizada } \\
\text { por IEP organizadas em } \\
\text { consórcios: nove principais e } \\
37 \text { vinculadas a elas. }\end{array}$ \\
\hline \multirow{2}{*}{$\begin{array}{l}\text { Prazo para o município solicitar a } \\
\text { Avaliação Externa, via sistema do } \\
\text { MS, de dois a seis meses, partir } \\
\text { da a homologação da adesão. No } \\
\text { ano de implantação do programa, } \\
\text { definiu-se a Avaliação Externa para } \\
\text { seis meses após a adesão. A partir } \\
\text { do } 2^{\circ} \text { ciclo, as equipes seriam } \\
\text { avaliadas a cada } 18 \text { meses. }\end{array}$} & \multicolumn{2}{|c|}{$\begin{array}{l}\text { Ao contratualizar o PMAQ-AB, o município assume que } \\
\text { participará da Avaliação Externa, sem a necessidade de } \\
\text { solicitação. }\end{array}$} \\
\hline & $\begin{array}{l}\text { Em caso de desistência de } \\
\text { equipes, o gestor deverá } \\
\text { informar no sistema as } \\
\text { não irão participar mais } \\
\text { da Avaliaçáo Externa. Não } \\
\text { aconteceu, foi visto na } \\
\text { Avaliaçáo Externa. }\end{array}$ & - \\
\hline $\begin{array}{l}\text { Solicitação da Avaliaçáo Externa } \\
\text { condicionada aos critérios de } \\
\text { permanência no programa e de } \\
\text { informação aos colegiados de } \\
\text { gestão local, e à alimentação no } \\
\text { sistema do MS de informaçóes } \\
\text { sobre as práticas das equipes com } \\
\text { maior grau de subjetividade e } \\
\text { variabilidade, a serem verificadas } \\
\text { na Avaliaçáa Externa. }\end{array}$ & - & - \\
\hline $\begin{array}{l}\text { O não cumprimento das } \\
\text { condiçôes para a permanência } \\
\text { e não solicitação da Avaliação } \\
\text { descredenciaria os municípios, } \\
\text { deixando de receber os recursos do } \\
\text { programa e ficando impedidos de } \\
\text { aderir por dois anos. }\end{array}$ & \multicolumn{2}{|c|}{$\begin{array}{l}\text { O não cumprimento das condições para a permanência resulta } \\
\text { em } \underline{\text { desclassificação da equipe, assim, o município deixa de }} \\
\text { receber os incentivos financeiros. }\end{array}$} \\
\hline $\begin{array}{l}\text { Utilizou instrumento próprio para } \\
\text { a avaliação das EAB composto por: } \\
\text { Módulo I (Observação na Unidade } \\
\text { de Saúde); Módulo II (Entrevista } \\
\text { com Profissional e Verificação } \\
\text { de Documentos na Unidade de } \\
\text { Saúde); e Módulo III (Entrevista na } \\
\text { Unidade de Saúde com Usuário). }\end{array}$ & \multicolumn{2}{|c|}{$\begin{array}{l}\text { Utilizou instrumento próprio para cada modalidade de } \\
\text { equipe. O instrumento da EAB com a mesma estrutura do } \\
1^{\circ} \text { ciclo. O instrumento da ESB composto pelo Módulo } \\
\text { V (Observação na UBS), Módulo VI (Entrevista com } \\
\text { o profissional e verificaçáo de documentos na UBS). O } \\
\text { instrumento do NASF composto pelo Módulo IV (Entrevista } \\
\text { com o profissional e verificaçáo de documentos na UBS). }\end{array}$} \\
\hline
\end{tabular}

continua... 


\begin{tabular}{|c|c|c|}
\hline $1^{\circ}$ ciclo & $2^{\circ}$ ciclo & $3^{\circ}$ ciclo \\
\hline \multicolumn{3}{|c|}{$\begin{array}{l}\text { O instrumento contempla aspectos relacionados com as políticas e programas da PNAB. A cada ciclo } \\
\text { do programa, os instrumentos seriam revisados, e novos "Padróes de Qualidade" foram definidos. }\end{array}$} \\
\hline- & \multicolumn{2}{|c|}{$\begin{array}{l}\text { Foram definidos diferentes tipos de Padrões para os } \\
\text { instrumentos: geral, essencial, estratégico ou obrigatório, com } \\
\text { conceitos e objetivos diferentes. }\end{array}$} \\
\hline $\begin{array}{l}\text { Módulo IV (online) } \\
\text { disponibilizado pelo MS para ser } \\
\text { preenchido pelos gestores e equipes } \\
\text { com informaçôes complementares } \\
\text { às coletadas na Avaliação Externa. }\end{array}$ & $\begin{array}{l}\text { Módulo IV renomeado para } \\
\text { Modulo Eletrônico com } \\
\text { objetivo de obter informaçóes } \\
\text { complementares às da } \\
\text { Avaliação Externa e sobre os } \\
\text { indicadores. }\end{array}$ & $\begin{array}{l}\text { Modulo Eletrônico } \\
\text { disponibilizado para obter } \\
\text { informaçốes complementares } \\
\text { às coletadas na Avaliação } \\
\underline{\text { Externa. }}\end{array}$ \\
\hline
\end{tabular}

Fonte: as autoras.

Inicialmente, o não cumprimento de alguns critérios levaria à exclusão dos municípios, impedindo de receber o recurso financeiro e aderir ao programa. Contudo, a solicitação da Avaliação Externa e o prazo de 18 meses para avaliação nunca foram efetivados, e sobre as condiçóes de permanência, apenas a não alimentação do SI desclassificou equipes, impactando no repasse do incentivo financeiro para os municípios (quadro 3).

Mudanças no instrumento de Avaliação Externa estavam previstas. Ele foi adaptado para os tipos de equipe e modificado a cada ciclo, assim como o Módulo Eletrônico. A principal alteração no extenso instrumento refere-se aos "padrões de qualidade" que, a partir do $2^{\circ}$ ciclo, passaram a ter diferentes classificaçóes (ver quadro 3), com base na necessidade de adequaçáo dos critérios e parâmetros, na experiência e os resultados do ciclo anterior, e a partir de consensos criados entre MS, outros representantes da tripartite, e a academia (BRASIL, 2013b; FAUSTO; FONSECA, 2013; CAVALCANTI, 2014). Ao longo dos ciclos, a composição da Certificação das equipes foi alterada. Houve a decomposição do percentual do monitoramento ( $2^{\circ}$ ciclo), em razáo de mudança do SI. No $3^{\circ}$ ciclo, os indicadores passaram a ter mais peso no desempenho, reduzindo na mesma proporção o percentual da Avaliação Externa (quadro 4). Tal medida pode indicar maior aposta no monitoramento dentro do programa, questão já comentada. 
Quadiro 4. Certificação do PMAQ-AB por ciclo

\begin{tabular}{|c|c|c|}
\hline $1^{\circ}$ ciclo & $2^{\circ}$ ciclo & $3^{\circ}$ ciclo \\
\hline $\begin{array}{l}\text { Composição do desempenho } \\
\text { final das equipes no PMAQ- } \\
\text { AB: } \\
\text { Realização de Autoavaliação } \\
\text { (10\%); } \\
\text { Verificação do desempenho nos } \\
\text { indicadores de saúde (20\%); } \\
\text { Verificação de evidências para } \\
\text { os padrôes de qualidade da } \\
\text { Avaliaçáo Externa (70\%). }\end{array}$ & 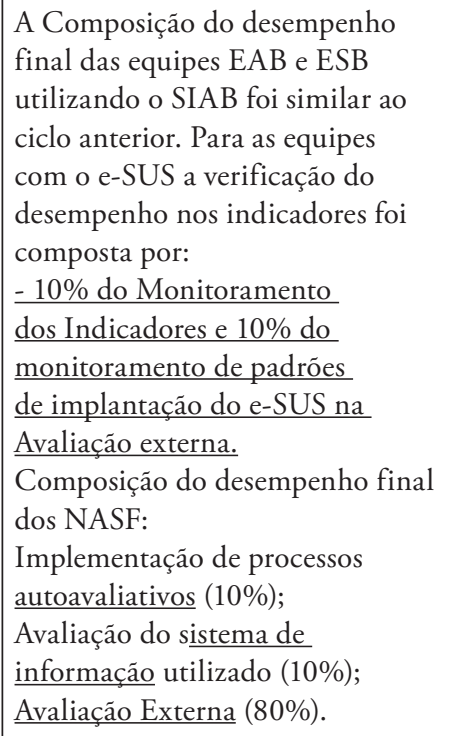 & $\begin{array}{l}\text { Composição do desempenho } \\
\text { final das equipes: } \\
\text { Implementação de processos } \\
\text { autoavaliativos (10\%); } \\
\text { Avaliação dos indicadores } \\
\text { contratualizados (30\%); } \\
\text { Avaliação Externa (60\%). }\end{array}$ \\
\hline \multicolumn{2}{|c|}{$\begin{array}{l}\text { Metodologia para cálculo do desempenho com base nos Estratos, } \\
\text { com o intuito de assegurar maior equidade na comparaçáo } \\
\text { das equipes no processo de Certificação. Os municípios foram } \\
\text { distribuídos em Estratos considerando aspectos sociais, econômicos } \\
\text { e demográficos. }\end{array}$} & $\begin{array}{l}\text { Metodologia para cálculo do } \\
\text { desempenho baseada em faixas } \\
\text { de pontuaçáo somadas aos } \\
\text { critérios de cumprimento dos } \\
\text { "Padróes de qualidade". }\end{array}$ \\
\hline $\begin{array}{l}\text { O desempenho de cada equipe } \\
\text { foi comparado com o das as } \\
\text { demais. Propôs no } 2^{\circ} \text { ciclo } \\
\text { agregar a comparaçáo da } \\
\text { evolução da própria equipe. }\end{array}$ & $\begin{array}{l}85 \% \text { desempenho de cada } \\
\text { equipe foi comparado com o das } \\
\text { demais, e } 15 \% \text { foi comparado ao } \\
\underline{\text { seu desenvolvimento entre uma }} \\
\text { Certificaçáo e outra. }\end{array}$ & $\begin{array}{l}\text { As pontuaçóes alcançadas por } \\
\text { cada equipe a classificou em } \\
\text { uma das faixas de pontuação. }\end{array}$ \\
\hline $\begin{array}{l}\text { Categorias de desempenho: } \\
\text { Insatisfatório; Regular; Bom; } \\
\text { e Ótimo. } \\
\text { No mesmo ciclo as categorias } \\
\text { foram modificadas para: } \\
\text { Insatisfatório; Mediano ou } \\
\text { acima da média; Acima da } \\
\underline{\text { média; e Muito acima da }} \\
\text { média. Também houve equipes } \\
\text { desclassificadas. }\end{array}$ & $\begin{array}{l}\text { A classificação dos desempenhos } \\
\text { baseou-se a distribuiçáo da Curva } \\
\text { de Gauss: } 50 \% \text { das equipes } \\
\text { com os menores desempenhos } \\
\text { classificadas como: Mediano ou } \\
\text { abaixo da média; } 34 \% \text { das equipes } \\
\text { com desempenho intermediário } \\
\text { classificadas como Muito acima } \\
\text { da média; } 16 \% \text { das equipes } \\
\begin{array}{l}\text { com os maiores desempenhos } \\
\text { classificadas como Muito acima }\end{array} \\
\text { da média. Também houve equipes } \\
\text { desclassificadas. }\end{array}$ & $\begin{array}{l}\text { Categorias de desempenho: } \\
\text { Desclassificada; Insatisfatória; } \\
\text { Ruim; Regular; Bom; Muito } \\
\text { bom; e Ótimo. }\end{array}$ \\
\hline
\end{tabular}

Fonte: as autoras. 
O peso da Autoavaliação sugere sua importância no PMAQ-AB em comparação aos outros componentes da Certificação. Para o MS, a relevância dos processos autoavaliativos comprometidos com a melhoria contínua da qualidade está em potencializar outros processos, contribuindo para a reorientação das práticas (BRASIL, 2017a), crença endossada por Cruz (2014), que menciona o potencial da autoavaliação como mecanismo que contribui para a organização do processo de trabalho e, consequentemente, para alcance de melhores resultados na AB. É mais uma oportunidade de mobilizar a participação e aproximação de diversos atores nos momentos de discussáo e decisão, para possam se sentir parte do processo para a construção de alternativas voltadas à mudança (BERTUSSO; RIZZOTTO, 2018).

Nas normativas do programa, as bases para modificação na metodologia de Certificação das equipes não estão claras. De repente, abandonou-se a metodologia do estrato de municípios e adotou-se ponto de corte para cada desempenho, impossibilitando ao final a comparação do desempenho da equipe. A parte do desempenho vinculado à comparação da evolução da equipe também foi suprimida. As classificações de desempenho foram alteradas, chegando no $3^{\circ}$ ciclo a se aproximar do proposto a priori no $1^{\circ}$ (quadro 4).

O PMAQ-AB atrelou o repasse de recursos federais para os municípios ao desempenho alcançado a partir da verificação de elementos predefinidos, segundo regras do programa. A Portaria $n^{\circ} 1.089$, de 28 de maio de 2012, definiu valores mensais de incentivo financeiro denominado como Componente de Qualidade do Piso de Atenção Básica Variável (PAB Variável), por tipo de equipe, para repasse conforme desempenho alcançado pelas equipes de $\mathrm{AB}$ na Certificação. Esses valores se estenderam ao NASF com sua inclusão no programa em 2013 (BRASIL, 2013a). Posteriormente, a Portaria no 2.777, de 4 de setembro de 2018, definiu os valores financeiros vinculados ao PMAQ-AB obedecendo à nova metodologia de Certificação, com adaptação dos valores a serem repassados por desempenho ao orçamento global destinado ao programa.

Assim, nos dois primeiros ciclos, os valores repassados para os municípios tinham como base o PAB Variável de cada modalidade. No último ciclo, não se sabia a priori quanto o município receberia por equipe, já que era preciso certificá-las primeiro para depois distribuir o recurso do orçamento fixado de acordo com a Certificação da equipe. No geral, ao longo do PMAQ, os recursos repassados para os municípios 
cresceram, de forma incremental acompanhando a crescente participação de equipes, chegando a um total de mais de 12 bilhóes até agosto de 2019 (BRASIL, 2019; 2020).

Essa mudança parece estar relacionada com o contexto de crise econômica com redução de recursos para a saúde. Os primeiros ciclos do PMAQ-AB ocorreram em um período de aumento no investimento para AB (PINTO; KOERNER; SILVA, 2012), mas o último ciclo já se iniciou em um cenário de restrição orçamentária (MACHADO; LIMA; BAPTISTA, 2017), tornando o recurso disponível para o programa menos elástico.

\section{Recontratualização}

A Recontratualização significa a permanência da equipe no PMAQ-AB e ocorria no mesmo momento da Adesão e Contratualização. Para os municípios, essa fase se baseia na concordância entre gestores e equipes para incremento de novos padrôes e indicadores de qualidade considerando o contexto local do SUS e os resultados alcançados no programa. Mas, assim como ocorreu em outros momentos propostos pelo programa, verificou-se que aproximação e diálogo entre gestores e profissionais da $A B$ em diversos lugares era fictícia (FAUSTO; FONSECA, 2013; GOMES; BARBOSA; FERLA, 2016; SAMPAIO, 2016).

Além disso, a morosidade na divulgação dos resultados (FAUSTO; FONSECA, 2013) e a forma de publicização dos relatórios também dificultaram a apropriação e uso desses resultados pelos gestores e equipes. Uma crítica atribuída ao programa destaca problemas na dinâmica de desenvolvimento do PMAQ-AB, ao considerar que o processo instituído não propiciava a reflexão e negociação pelos atores locais executores das açôes de $\mathrm{AB}$, inibindo a consolidação das açôes no nível local de atuação das equipes (FAUSTO; FONSECA, 2013; SAMPAIO, 2016).

Como consequência das diversas mudanças observadas, existem opinióes que centram na ineficiência do programa em avaliar (SOSSAI et al., 2016). Outras visões creem na capacidade de exprimir parte das várias realidades, mesmo sabendo da ocorrência de falseamento dos cenários para atingir bons desempenhos (FAUSTO; FONSECA, 2013; CAVALCANTI, 2014; GOMES; MERHY, 2016; SAMPAIO, 2016). A mobilização de gestores e profissionais da $A B$, no entanto, também mostram o outro lado da "maquiagem", indicando que a melhoria é possível (FAUSTO; FONSECA, 2013). Portanto, ainda que alguns processos evidenciem paradoxos, diversas experiências mostram que o programa provocou deslocamentos que 
apontam para outras possibilidades, como maior abertura para a ideia de é possível induzir mudança no modo de produzir saúde mediante a adoção de novos arranjos de gestão e de cuidado, pautados em avanços incrementais, ainda que provisórios (FEUERWERKER; MERHY; BERTUSSI, 2016).

Observou-se também que os documentos do programa, de forma geral, versam sobre promover a satisfação dos usuários. Mais especificamente, no instrumento de Avaliação Externa há uma parte focada em verificar a satisfação e percepção dos usuários quanto ao serviço de saúde, evidenciando que o PMAQ-AB avança na perspectiva de considerar a opinião dos usuários na avaliação. Uchimura e Bosi (2002) já haviam destacado a importância da satisfação do usuário para a avaliação da qualidade em saúde que, sem dúvida, tem que ser considerada junto a outros elementos que determinam a qualidade dos serviços de saúde, como competência profissional, acessibilidade, eficácia e eficiência.

Desta forma, o que interessa em uma avaliação não é a descoberta de uma verdade única, mas o esforço por verificar situaçôes e práticas e validar o seu significado. Desta forma, é importante adotar uma perspectiva mais compreensiva sobre as características das açôes avaliativas no Brasil, onde persiste uma ideia negativa da avaliação em saúde, frequentemente associada a um processo punitivo ou constrangedor; com isso, tende a ser mais difícil estabelecer uma cultura de avaliação continuada (USHIMURA; BOSI, 2002).

\section{Considerações finais}

Ao longo dos anos, o PMAQ-AB tornou-se um programa complexo e difícil de ser compreendido, e as mudanças no seu arcabouço teórico contribuíram para isso. As constantes alteraçôes geram dúvidas e questionamentos, podendo até ter causado descrença e desmobilização dos atores, fragilizando o programa.

Entretanto, qualquer análise não pode prescindir de ressaltar a conjuntura macropolítica institucional do MS, sob o risco de incorrer em uma visão parcial e descontextualizada, haja vista que o agitado cenário de mudanças ocorridas no governo federal e, especialmente, no MS no período termina por influenciar os rumos do programa. As mudanças no PMAQ-AB dialogam com esses eventos, seu surgimento ocorreu em um contexto de priorização da $A B$ e foi se desfazendo, sobretudo a partir da última revisão da PNAB e emergência de novos atores políticos com interesses e concepçóes opostas aos que o criaram. 
Em geral, as justificativas para as modificações não foram devidamente esclarecidas; por vezes os documentos apenas citavam necessidade técnica e/ou política, sem explicitar os critérios, intençôes ou evidências. Sendo assim, essa lacuna pode ser foco de investigaçóes futuras que busquem por meio de outros caminhos metodológicos explicitar os aspectos que contribuíram para as mudanças. Defendese que dentro da dinâmica de um processo avaliativo, os critérios e métricas variem ao longo do tempo, em reconhecimento a novas possibilidades que surgem. Todavia, dentro de uma avaliação contínua, é fundamental que as mudanças implementadas sejam explicadas, servindo com guia para o aprimoramento das açóes, a partir do reconhecimento da necessidade de ajustes pelos avaliados.

O PMAQ-AB, por sua vez, também se destaca como uma oportunidade de avançar com a institucionalização do monitoramento e avaliação da $\mathrm{AB}$ no intuito de impulsionar avanço na qualidade da atenção à saúde no Brasil, evidenciando, para isso, a necessidade de se pensar estratégias que dialoguem com a realidade local diante da intensa heterogeneidade de configuraçôes da $\mathrm{AB}$ nos municípios.

Com o PMAQ-AB, entrou em cena um desenho de monitoramento e avaliação para a $\mathrm{AB}$, que considerou diversos aspectos relacionados à $\mathrm{PNAB}$ e valorizou também a opinião do usuário e a inédita incorporação de mecanismos de remuneração e incentivos por desempenho nacionalmente, atrelando o repasse de recurso federal ao desempenho alcançado no programa. Além disso, fomentou a utilização da autoavaliação como forma de refletir sobre o trabalho e balizar o planejamento das açôes; ousou ao definir novos indicadores de saúde para o monitoramento das equipes de $\mathrm{AB}$, incluindo os NASF; estabeleceu uma cooperação interinstitucional com dezenas de instituiçôes de ensino e pesquisa que inovou ao definir uma metodologia e logística aplicada à avaliação de um grande volume de serviços e equipes. Essas apostas são relevantes por serem inovadoras ou promissoras e, ao mesmo tempo, desafiadoras para a implementaçáo do programa e para a AB.

Os atuais problemas da Atenção Básica estão relacionados a fatores de diversas ordens, o que exige dos gestores com poder decisão a elaboração de propostas para seu enfrentamento, assumindo um papel protagonista na condução das políticas públicas de saúde. Nesse sentido, o PMAQ-AB representa uma inovação no SUS, que mobilizou a agenda e induziu um amplo debate em relação aos desafios, prioridades e intervençôes para melhorar os serviços de saúde. Um legado construído pelo programa aponta para a centralidade da Atenção Básica e necessidade de mobilização 
de atores diversos e a democratização das ideias visando ao refinamento da política de saúde. Perceber seus limites e incompletudes ajuda na construçáo de outras iniciativas avaliativas no campo da saúde, na perspectiva de buscar soluçôes eficazes para superar os desafios que inibem a consolidação da Atenção Básica no SUS. ${ }^{2}$

\section{Referências}

ASSOCIAÇÃO BRASILEIRA DE SAÚDE COLETIVA (ABRASCO). Contribuição da Rede APS ao debate sobre as recentes mudanças na política de Atenção Primária. 2019. Disponível em: https://www.abrasco.org.br/site/eventos/congresso-brasileiro-de-ciencias-sociais-e-humanasem-saude/contribuicao-dos-pesquisadores-da-rede-aps-ao-debate-sobre-as-recentes-mudancasna-politica-de-atencao-primaria/43125/. Acesso em: 02 abr. 2020.

ALBUQUERQUE, C.; MARTINS, M. Indicadores de desempenho no Sistema Único de Saúde: uma avaliaçăo dos avanços e lacunas. Saúde Debate [online], Rio de Janeiro, mar. 2017, p. 118-137. Disponível em: https://www.scielo.br/pdf/sdeb/v41nspe/0103-1104-sdeb-41nspe-0118.pdf. Acesso em: 10 mar. 2020.

BERTUSSO, F. R.; RIZZOTTO, M. L. F. PMAQ na visão de trabalhadores que participaram do programa em Regiáo de Saúde do Paraná. Saúde Debate, Rio de Janeiro, 42, n. 117, p. 408419, jun. 2018.

BRASIL. Ministério da Saúde. Portaria no 1.654, de 19 de julho de 2011. Institui no âmbito do Sistema Único de Saúde o Programa Nacional de Melhoria do Acesso e da Qualidade da Atenção Básica e o Incentivo Financeiro do PMAQ. Diário Oficial da Uniāo, Brasília, DF, 10 abr. 2020. Disponível em: http://bvsms.saude.gov.br/bvs/saudelegis/gm/2011/prt1654_19_07_2011.html. Acesso em: 10 abr. 2020.

- Ministério da Saúde. Programa Nacional de Melhoria do Acesso e da Qualidade da Atenção Básica: manual instrutivo. Brasília: MS, 2012a.

. Ministério da Saúde. Política Nacional de Atenção Básica. Brasília, DF, 2012 b.

. Ministério da Saúde. Instrumento de Avaliação Externa do Saúde Mais Perto de Você: acesso e qualidade. Brasília: MS, 2012c. Disponível em: http://189.28.128.100/dab/docs/ portaldab/documentos/instrumento_coleta_avaliacao_externa. pdf. Acesso em: 12 mar. 2020.

. Ministério da Saúde. Manual Instrutivo para as Equipes de Atenção Básica. Brasília: MS; 2013a. Disponível em: http://189.28.128.100/dab/docs/portaldab//publicacoes/manual_ instrutivo_PMAQ_AB2013.pdf. Acesso em: 02 abr. 2020.

. Ministério da Saúde. Instrumento de Avaliação Externa do PMAQ. Brasília: MS, 2013b. Disponível em: http://189.28.128.100/dab/docs/portaldab/documentos/instrumento_ae_sfp. pdf. Acesso em: 12 mar. 2020. 
- Ministério da Saúde. Nota Metodológica da Certificação das Equipes de Atenção Básica participantes do PMAQ. Brasília: MS, 2013c. Disponível em: http://189.28.128.100/dab/docs/ portaldab/documentos/nota_metodologica_pmaq.pdf. Acesso em: 25 mar. 2019.

. Ministério da Saúde. Portaria no 1.645, de 2 de outubro de 2015. Dispóe sobre o Programa Nacional de Melhoria do Acesso e da Qualidade da Atenção Básica (PMAQ-AB). Diário Oficial da União, Brasília, DF, 05 out. 2015a. Disponível em: http://pesquisa.in.gov.br/imprensa/jsp/ visualiza/index.jsp?data=05/10/2015\&jornal=1\&pagina $=668 \&$ total Arquivos $=908$. Acesso em: 02 abr. 2020.

- Ministério da Saúde. Programa Nacional de Melhoria do Acesso e da Qualidade da Atenção Básica: manual instrutivo para as Equipes de Atenção Básica e NASF. Brasília: MS; 2015b. Disponível em: http://189.28.128.100/dab/docs/portaldab/documentos/Manual_ Instrutivo_3_Ciclo_PMAQ.pdf. Acesso em: 02 abr. 2020.

- Ministério da Saúde. Nota Metodológica da Certificação das Equipes de Atenção Básica. Brasília: MS, 2015c. Disponível em: http://189.28.128.100/dab/docs/portaldab/documentos/ nota_metodologica_2_ciclo_pmaq.pdf. Acesso em: 25 mar. 2019.

- Nota Metodológica da Certificação dos Núcleos de Apoio à Saúde da Família. Brasília: MS, 2015d. Disponível em: http://189.28.128.100/dab/docs/portaldab/documentos/nota_ metodologica_nasf.pdf. Acesso em: 25 mar. 2019.

. Autoavaliação para melhoria do acesso e da qualidade da atenção básica-AMAQ. Brasília: MS, 2017a. Disponível em: http://189.28.128.100/dab/docs/portaldab/publicacoes/amaq_2017. pdf. Acesso em: 25 mar. 2019.

. Instrumento de Avaliação Externa para as EAB, Saúde Bucal e NASF. Brasília: MS, 2017b. Disponível em: http://189.28.128.100/dab/docs/portaldab/documentos/instrumento_ amaq_ab_sb_3ciclo.pdf. Acesso em: 12 mar. 2020.

. Nota Metodológica da Certificação das Equipes de Atenção Básica participantes do PMAQ. Brasília: MS, 2018a. Disponível em: http://189.28.128.100/dab/docs/portaldab/documentos/ nota_metodologica_pmaq.pdf. Acesso em: 25 mar. 2019.

- Nota Metodológica da Certificação do Núcleo de Ampliado de Saúde da Família. Brasília: MS, 2018b. Disponível em: http://189.28.128.100/dab/docs/portaldab/documentos/ nota_metodologica_pmaq.pdf. Acesso em: 25 mar. 2019.

Ministério da Saúde. SAGE: Sala de Apoio à Gestão Estratégica [homepage na Internet]. Brasília. Disponível em: http://sage.saude.gov.br/\#. Acesso em: 24 ago. 2019.

- Ministério da Saúde. eGestor Atenção Básica. PMAQ-AB: Relatório de pagamento. [homepage na Internet]. Brasília. Disponível em: https://egestorab.saude.gov.br/paginas/ acessoPublico/relatorios/relPagamentoPmaq.xhtml. Acesso em: 14 set. 2020. 
CAVALCANTI, P. C. D da S. Atenção básica no Brasil: desafios e iniciativas para qualificação. Brasília: Universidade de Brasília, 2014. 133 p. Dissertação (Mestrado em Saúde Pública).

CRUZ, M. M. D. Usos do planejamento e autoavaliação nos processos de trabalho das equipes de Saúde da Família na Atenção Básica. Saúde debate, Rio de Janeiro, 38, n. esp., p. 124-139, out. 2014.

FAUSTO, M. C. R.; FONSECA, H. M. S. Rotas da atenção básica no Brasil: experiências do trabalho de campo PMAQ-AB. Rio de Janeiro: Saberes Editora, 2013.

FEUERWERKER, L. C. M.; MERHY, E. E.; BERTUSSI, D. C. Avaliação compartilhada do cuidado em saúde: surpreendendo o instituído nas redes. 1. ed. Rio de Janeiro: Hexis, 2016. 440 p. GOMES, L. B.; BARBOSA, M. G.; FERLA, A. A. Atenção Básica: olhares a partir do Programa Nacional de Melhoria do Acesso e da Qualidade da Atenção Básica. Porto Alegre: Rede Unida, 2016.

GOMES, L. B.; MERHY, E. E. Uma análise política do Programa Nacional de Melhoria do Acesso e da Qualidade da Atenção Básica. In: GOMES, L. B.; BARBOSA, M. G.; FERLA, A. A. Atenção básica: olhares a partir do Programa Nacional de Melhoria do Acesso e da Qualidade da Atenção Básica. Porto Alegre: Rede UNIDA, 2016. p. 49-73.

MACHADO, C. V.; LIMA, L. D. D.; BAPTISTA, T. W. D. F. Políticas de saúde no Brasil em tempos contraditórios: caminhos e tropeços na construção de um sistema universal. Cad. Saúde Pública, Rio de Janeiro, 33, n. supl. 2, e00129616, p. 143-161, 02 out. 2017.

MATTOS, R. A. D.; BAPTISTA, T. W. D. F. Sobre Política (ou o que achamos pertinente refletir para analisar políticas). In: MATTOS, R. A. D.; BAPTISTA, T. W. D. F. Caminhos para análise das politicas de saúde. 1. ed. Porto Alegre: Rede UNIDA, 2015. p. 83-149.

MELO, E. A. et al. Mudanças na Política Nacional de Atenção Básica: entre retrocessos e desafios. Saúde Debate, Rio de Janeiro, 42, n. n. esp 1, p. 38-51, set. 2018.

PINTO, H. A.; KOERNER, R. S.; SILVA, D. C. A. Prioridade se traduz em mais e melhores recursos para a Atenção Básica. Brasília: Conselho Nacional de Secretarias municipais de Saúde, 2012. Disponível em: <https://www.conasems.org.br/prioridade-se-traduz-em-mais-emelhores-recursos-para-a-atencao-basica-por-heider-pinto//.>. Acesso em: 02 abr. 2020.

PINTO, H. A.; SOUSA, N. A.; FERLA, A. A. O Programa Nacional de Melhoria do Acesso e da Qualidade da Atenção Básica: várias faces de uma política inovadora. Saúde Debate [online], Rio de Janeiro, 38, n. esp, p. 358-372, out. 2014. Disponível em: https://www.scielo.br/pdf/ sdeb/v38nspe/0103-1104-sdeb-38-spe-0358.pdf. Acesso em: 30 mar. 2020.

REDE DE PESQUISA EM ATENÇÃO PRIMARIA À SAÚDE DA ABRASCO (REDE APS). Contribuição para uma agenda política estratégica para a Atenção Primária à Saúde no SUS. Saúde debate, 42, n. esp, p. 406-430, set. 2018. 
RODRIGUEZ, M. R.; LEÃO, M. A.; SOUZA, N. K. T. D. Monitoramento e supervisão do Núcleo de Apoio à Saúde da Família (NASF) em uma região administrativa do Distrito Federal utilizando-se análise de entrevistas. Rev Bras Med Fam Comunidad, Rio de Janeiro, v. 9, n. 30, p. 38-44, jan. 2014.

SAMPAIO, J. et al. PMAQ-AB: a experiência local para a qualificação do programa nacional. Rev enferm UFPE online, Recife, v. 10, n. supl 5, p. 4318-4328, 2016. Disponível em: https:// periodicos.ufpe.br/revistas/revistaenfermagem/article/viewFile/11179/12720. Acesso em: 25 mar. 2019.

SOSSAI, T. A. et al. Evidências sobre o Programa Nacional de Melhoria do Acesso e da Qualidade da Atenção Básica. Rev. Bras. Pesq. Saúde, Vitória, v.18, n. 1, p. 111-119, jan-mar 2016.

UCHIMURA, K. Y.; BOSI, M. L. M. Qualidade e subjetividade na avaliação de programas e serviços em saúde. Cad. Saúde Públ, Rio de Janeiro, v. 18, n. 6, p. 1561-1569, nov.-dez 2002.

\section{Notas}

${ }^{1} \mathrm{O}$ estudo dispensou avaliação por comitê de ética, uma vez que utilizou documentos públicos como fontes. Também não recebeu apoio financeiro para sua realização e não há conflitos de interesse.

${ }^{2}$ P Cavalcanti: Idealização, pesquisa, produção e revisão do artigo. M. Fernandez: Pesquisa, produção e revisão do artigo 


\section{Abstract}

National Program for Access and Quality Improvement in Primary Care: an analysis of the main regulatory changes

This article carried out an analysis of the main changes in the normative framework of the National Program for Access and Quality Improvement in Primary Care, based on official documents from the Ministry of Health released from July 2011 to July 2019. The findings reveal that most changes were not clear, making it difficult to understand the design of the program and to monitor the results of primary care teams. There were changes in the overall design of the program and more intrinsically to the phases or components. The architecture of the phases was modified; the rules for joining the program; how to check self-assessment; the monitoring of indicators due to the implementation of a new information system or due to technical deficiencies in the use of a given indicator; the external evaluation in relation to the rules for requesting and deadlines for receiving the evaluation, the teams' disqualification, and the parameters and method adopted; and certification more radically in the valuation of the components and in the calculation methodology and classification categories of the teams. The program bet on several strategies for qualifying primary care. Although with limitations and incompleteness, perceiving them is an opportunity to seek viable solutions for the refinement of health policy.

> Keywords: public health policy; Primary Health Care; monitoring; health care quality, access, and evaluation; quality improvement. 